\title{
The effect of augmented reality assisted geometry instruction on students' achievement and attitudes
}

\author{
EMIN İBİLİ and SAMİ ŞAHIN
}

\begin{abstract}
In this study, geometry instruction's academic success for the students and their attitudes towards mathematics which is supported by education materials of Augmented Reality (AR) and its effect on the acceptance of AR and its usage by teachers and students have been researched. Under this research, ARGE3D software has been developed by using augmented reality technology as for the issue of geometric objects that is contained in the mathematics curriculum of 6th class of primary education. It has been provided with this software that three-dimensional static drawings can be displayed in a dynamic and interactive way. The research was conducted in two different schools by an experiment and control group. In the process of data collection, Geometry Achievement Test (GAT), Geometric Reasoning Test (GRT), Attitudes Scale for Mathematics (ASM), students' math lecture notes, semi-structured interviews with teachers and students and observation and video recordings were used. Results showed that geometry instruction with ARGE3D increased students' academic success. In addition, it was found that geometry instruction with ARGE3D became more effective on students' attitudes that had negative attitudes towards mathematics and it also provided support to reduce fear and anxiety
\end{abstract}

Key words and phrases: augmented reality, mathematics and geometry teaching, attitude, achievement.

ZDM Subject Classification: U10, G10, G20, C20, D60.

\section{Introduction}

Since three-dimensional geometric objects are taught on two dimensional plane geometry that are contained in geometry lessons, it is known that students have problems in their academic achievements and they also have negative 
attitudes towards geometry classes [1-6]. Geometry is a course that is closely related to students' spatial skills. Although there is three dimensional space geometry in the background of curriculum in order to develop spatial skills, the main emphasis is made on two-dimensional plane geometry [3]. For example, it is impossible to find in the comparison of a sphere and a cube intuitively that is bigger than the other. Therefore, in order to compare two objects correctly and easily, there is a need for manipulations that are three dimensional [5]. If only the mathematical formulas and regulating geometry are used to make a comparison of the volumes of the two bodies, students are inadequate to understand these formulas and objects.

According to Piaget, logical-mathematical information can be configured by abstractions based on thinking, while physical information are being created by abstractions that are based on observation or experiment [7]. However, these two types of information are not independent from each other for the younger children and physical information plays an important role in understanding many abstract mathematical concepts such as the concept of number. Therefore, the course consents for the behaviors that are desired to be provided to primary school children should be supported by concrete materials that will appeal to their different sensory organs. According to Bruner, children express their thoughts in operational, imaginary and symbolic ways [8]. The use of concrete materials such as physical objects provide them to express their thoughts via operational navigations. In this regard, it can be said that the use of virtual reality or virtual learning material is a powerful tool in the teaching of geometry, it also teaches to discover information, it facilitates interaction between students and it helps users to understand concepts, layouts and relationships by observing dynamics of virtual concepts. Moreover, the applications that are running with these software provide students to make movements, shrinkages, shapes turning in their minds easily and it makes a positive impact on their dynamic visualization skills [5, 6].

Prisms, cylinders, pyramids, cubes cannot be seen via two dimensional software and creation of them time are rather time consuming. However, they can be easily created and can be viewed by turning from different angles via 3D mathematical software. Thus, the relationship between the structure, properties, and computational generalizations can be carried out easily [9]. In this regard, 3D math software contributes to the learning process in terms of embodying abstract concepts, students learning with less cognitive effort and facilitating the complex information processing. The majority of the research in this area shows that using dynamic geometry software in teaching improves students' academic achievement 
and spatial visualization skills [10]. When the effectiveness of virtual environments and tangible object for using development of spatial skills in the literature examined, it can be seen that different results were obtained by the researchers. Fahlberg-Stojanovska and Trifunov found out that teaching geometry by the help of GeoGebra geometry software improved academic achievement [11]. Similarly, Selcuk and Bilgici (2011) revealed that teaching with GeoGebra brings more success to students in the teaching of polygonal subjects [12]. Arbain and Shukor indicated that teachers and students have found GeoGebra as an effective tool to learn mathematics [13]. Guven and Kosa determined that Cabri 3D, which is dynamic geometry software, have positive effects on mathematics teacher candidates' spatial skills [14]. However, Eraso found out that using virtual environment sketchpad was not effective for development of spatial visualization skills of tenth grade students [15]. Yildiz indicated that using virtual environment for the development of spatial visualization skills of elementary school students is effective, but it is not effective for their development of mental rotation skills [16]. Majority of the research related with 3D math software has remained limited to GeoGebra, Cabri 3D and Sketchpad software.

Even though the advances in computer technology provide new possibilities every day, in the point of acceptance and usage of these technological opportunities, it is seen that a teacher's perception seems not to be in sufficient level. An important reason for this is that the written course materials in the curriculum are still being the main source and tool of teaching activities. Because it is not easy to adopt innovations and put them into practice for teachers. In the literature, there are many studies revealing that teachers can not apply the new teaching programs and teaching-learning approaches suggested by these programs. The studies also reveal that teacher's thoughts, beliefs and attitudes are inconclusive because their beliefs about teaching and learning do not change, therefore teachers fail to execute the innovations and they are back to old teaching habits [17].

Course books and virtual learning objects can be used simultaneously with Augmented Reality (AR) technology that provides rich multimedia content by adding a layer of digital on images of the real world with new developing technologies. AR is a technology that provides a developed or enhanced view of the real-world with a user's text, voice and other additional information [18]. However, as in virtual reality, reality doesn't change place with the environment, instead of this, it uses real environment as a background and data, static images or dynamic 3D models can be added on the video image of the real environment 
simultaneously. When Azuma defined AR, he emphasized three characteristic as follows [19]:

- Combination of real and virtual

- Real-time interaction

- $3 \mathrm{D}$ recording

AR environments allow manipulations and offer the opportunity to learn by providing much more [20]. AR technologies place virtual items on a real word seamlessly and they provide for the students to learn by experiencing knowledge and skills. It is also possible to share information and experience among learners in AR environments [21]. In this environment, the learning content can be presented in a meaningful and tangible way including practical skills training. AR and virtual reality have common features such as navigation and interaction [20]. However, according to the virtual reality, AR has two more advantages. First, AR provides a shared experience in a real environment. Users can simultaneously work in a real environment with computer-generated objects. Second, AR provides tangible interaction. AR technology supports active participation of the student in creating their own knowledge structure with its interaction opportunities. With this technology, an individual finds an active learning opportunity by interacting with the environment, experiences rich things and captures a learning environment by discovering. AR instructional media courses are important in education in terms of attracting students' interests and attentions, encouraging students to use their imagination and creativity, developing spatial thinking skills and developing practical application skills.

In this study, ARGE3D software has been developed that provides 3D geometry materials to be added on the real image simultaneously, that increases the functional wealth of the environment and that permits user control on these materials. ARGE3D software's and AR supported geometry teaching's impact on attitudes and academic achievement of the students were investigated.

\section{Literature Review}

\subsection{Augmented reality and its use in learning}

Regarding augmented reality and its usage in education, AR supported instruction develops spatial skills of the students, it activates students during the 
course and keeps their interest high and it also provides an increase in their motivation. Bujak et al. stated that $\mathrm{AR}$ technologies used in mathematics education allow students to use the information in the real world and reduces the foreign cognitive load by making teaching attractive with virtual educational content [22]. Gutierrez et al. stated that the education made by AR supported books contribute to the development of spatial skills of the students, at the same time, the usage of these books is accepted as easy and useful technique and they show positive attitude towards AR-supported education [23].

AR technologies also support the situated learning technologies. Chang and Liu stated that AR technologies create a reliable representation in order to acquisite real world knowledge and authentic learning contexts provided by these environments significantly facilitate the transfer of students to different environments [24]. Mahadzir and Phung stated that all students were satisfied with English education supported with Popup Book that is augmented reality aided English Story book and they followed lessons in an exciting way, and consequently the success of the students in performance increased [25]. Di Serio et al. found out that the visual art education supported by AR technologies increases students' motivation and they have less cognitive effort when compared to a presentation based learning, so it provides easy learning [26]. In the studies related to AR supported education for the education of science and engineering, it was seen that AR supported teaching of science and engineering is beneficial in terms of inquirybased teaching, students develop their spatial skills and contribute to conceptual understanding. Borrero and Marquez stated that laboratory practices are quite important in terms of engineering education and distance education courses in these areas cut off communication between students and teachers due to various pedagogical factors [27]. However, they also stated that, in the AR supported experimental application environment, students are more successful and active, their motivation and interest is higher, in addition, teachers and students find AR application laboratory useful. Wojciechowski and Cellary proposed that at the end of teaching by using ARIES system, AR technology's success largely depends on the situations and quality of the consent learning and $3 \mathrm{D}$ content interactive learning environments for learning AR learning environments should be developed in order to realize reaction assay between hydrochloric acid and sodium hydroxide [28]. Due to these environments, the provided active participation is effective on perceived fun and provides motivation increase. Fonseca et al. stated that AR usage increase the motivation and participation of the students but it is a good system to visualize the simple models, but it is also less useful to visualize 
detailed, intricate architectural models and to manage projects with high levels of sound [29].

\subsection{Augmented reality and its use in Geometry learning}

The studies that are made for AR supported geometry teaching show that AR technologies facilitate the user-computer interaction and this interaction motivates students much more. In addition, in these studies, it was indicated that the instructions carried out with AR technology increase students' spatial skills, academic performance and the level of their interactions. It also indicates that these teachings raise their level of interest and perception, make the student activate and provide significant spatial improvements. For the acceptance and use of AR technology, it is seen that students and teachers find AR technology easy to use and they are satisfied with the teaching.

Kaufmann and Schmalstieg developed the software called as Construct3D that has a dynamic AR geometry software for mathematics and geometry education and also provides a collaborative multi-user learning opportunity [30]. They stated that in classroom environments where Construct3D software is used simplify the geometry teaching and it develops the spatial skills of the students. Thus, they stated that it is effective in imparting spatial skills such as spatial perception of the students, spatial visualization, mental rotations, spatial relations and spatial orientation. By Banu, AGORS3D (Augmented 3D Geometrical Objects Reconstructed from Sketches) software was developed for the students to better understand geometry [31]. Two dimensional geometric figures drawn by the users on a paper or on the computer were transformed into threedimensional objects via AGORS3D and three-dimensional geometric surfaces were obtained from two-dimensional images of the users. Furthermore, footprints of these three-dimensional virtual objects were created on these markers that consisted of computer drawings by using AR and they were turned into objects that can be moved and that provides the opportunity to interact. Thus, they provided for three-dimensional static images to be displayed as more dynamic and interactive. Domíngueza et al. compared instructions that were carried out with three different technologies including virtual reality, augmented reality and PDF3D with the aim to improve spatial skills in graphic design [32]. As a result of the study, the students' level of satisfaction that were instructed with PDF3D technologies and virtual reality had similar levels but the students' satisfaction level that were instructed with AR had higher levels when compared to other groups. 


\section{Methodology And Methods}

The aim of the study is to reveal the effect of the geometry instruction that is supported by AR technologies to the academic achievements and attitudes of the students. The study was conducted in four classes that are experimental and control group including 6th class and two different state schools located in the center of Aksaray in Turkey. In one of the schools, experiment group has 26, control group has 28 students and the other school's groups both have 23 students. A teacher went to class in both schools in experimental and control groups. Geometric Objects Unit was covered that was in 6th class mathematics curriculum in all groups. Printed materials in experimental groups as an experimental application were supported by AR. The application that lasted 4 weeks had two hours per week was for the class environment with a computer and projector and the other two hours per week was for computer laboratory environment. For the purpose of the study, the following questions' answers were investigated.

- What are students' geometric thinking levels prior to the application of experimental and control groups?

- What are students' mathematics achievement levels prior to the application of experimental and control groups?

- Is there any significant difference between the experimental and control groups according to Geometry Achievement Test scores?

- Is there any significant difference between the experimental and control groups in terms of attitudes towards mathematics?

- What are the views of teachers and students for the use of AR technology?

\subsection{Data Collection}

In this study, an achievement test as a means of data collection, the Van Hiele Geometric Reasoning Test (VHGDT), attitudes towards mathematics scale were used. In addition, students and teachers with semi-structured interviews and observation applications with video recording technology for AR opinion on attitudes and intentions and effects were obtained.

Success in the development phase of testing was primarily prepared by the Ministry of Education Board of Education 6 Grade Mathematics Curriculum unit of geometric objects located in the gains are determined and prepared for the table of specifications. Then the set consisting of 11 learning objectives and a total of 92 questions in the question pool has been created. Questions derived from the 
diversity of mathematics teaching have been considered. Questions upholding the validity and scope of the choice made for the six elementary math teacher and three faculty members in the Department of Elementary Mathematics Education has been rated. 28 questions were prepared for the achievement of the test results. In Table 1, these learning objectives correspond to the achievement test items of the present study.

Table 1. Learning objectives related with the geometry instruction

\section{Learning objectives}

Identify basic elements of prisms

Draw different perspectives of 3 dimensional objects that are made up of unitsized cubes.

Explain liquid measuring units and converts them to each other.

Solve and pose problems related with liquid measuring units.

Solve and pose problems related with liquid measuring units.

Predict the volumes of rectangular prism, square prism and cube by using strategies.

Pose and solve problems related with rectangular prism, square prism and cube.

Explain volume measurement units and convert them among each other.

Explain the relationship between volume measurement units and liquid measurement units.

Calculate the surface areas of rectangular prism, square prism and cube.

Pose and solve problems related with surface areas of rectangular prism, square prism and cube.

The exam duration in the pilot application was decided to be 40 minutes and it was applied to a total of 175 seventh- class students in the center of Aksaray. As a result of the pilot application, 5 questions' index of item difficulty and degree of distinctiveness were lower, so they were removed from the exam within the opinions of teachers and students. At the end of the pilot study consisting of 23 items of the test item difficulty level of an average 0.49 ; the average level of distinctiveness 0.64 and KR- 20 internal consistency coefficient was found to be 0,737 . Thus, it was assumed to have the sufficient reliability and validity in the data collection to be used. At the end of the experimental procedure, one question was excluded due to low material value. At the end of the achievement test consisting of 22 items of the test item difficulty level of an average 0.49 ; the 
average level of distinctiveness 0.64 and KR- 20 internal consistency coefficient was found to be 0,775 . The internal consistency was 0,70 and if this would be taken into consideration, it can be said that the achievement test's reliability is good.

VHGDT test used in the study was developed by Usiskin [33] and it was adapted into Turkish, validity and reliability was provided by Duatepe [34]. While Cronbach Alpha reliability coefficient of the test for each factor in Usiskin's data was calculated between 0,65 and 0,79, it was calculated in Duatepe's data between 0,59 and 0,82 . In this study, it was calculated respectively $0,60,0,65$ and 0,77 . VHGDT each factor in testing, which of the concept of geometry is not that what level of achievement on people's concepts in geometry indicates how they think. In determining students' Van Hiele Geometric thinking levels, the weighted score calculation method was used by Usiskin.

To determine students' attitudes towards mathematics, Likert type mathematics education scale developed by Aşkar was used [35]. The scale was developed by administering it to 204 students studying at Middle East Technical Foreign Languages School. Scale for the implementation of the elementary school students within the scope of the validity and content validity of the equivalence of language expert opinions in determining the rate of the referenced content validity, and Davis technique was evaluated [36]. For this purpose, three faculty members in the Department of Elementary Mathematics Education, 6 elementary mathematics teacher and three measurement specialists were consulted. In this technique, experts checked the following points in each item in the scale:(a) appropriateness, (b) the substance must be revised slightly, (c) should be revised as serious and (d) are rated out of four points as unsuitable. For the calculation of the average content validity agent (a) and (b) divided by the expert on the substance, the total number of specialized content validity index is obtained. The obtained value is considered as 0,80 value instead of comparing by statistical criteria. All items of the scale were not removed from the scale due to being in acceptable level according to these criteria. However, some expressive adjustments were made based on feedback.

Semi-structured interviews were prepared with the aim to identify teachers' and students' opinions for educational effectiveness of geometry instruction supported by AR technologies and their intention for the usage of AR technologies in later lessons. In the scope of this aim, the following questions were investigated.

- What are the views of teachers and students for the usefulness of the augmented reality material? 
- What are the views of teachers and students for educational effectiveness of geometry instruction supported by augmented reality materials?

- What are the intentions and attitudes of teachers and students for the usage of augmented reality materials in later lessons?

The data obtained from these interviews were used in interpreting the findings obtained with quantitative data. The use of quantitative and qualitative data to support each other increases the reliability and validity of the research [37]. Experts were consulted in order to ensure the validity of the content-scope of the questions that are contained in semi-structured interview form while developing interview questions. In line with the opinions of experts, in the interview questions, the final shape has been determined after making the necessary adjustments. In addition, whole application was observed by the researcher and at the end of the application, semi-structured interviews were conducted with experiment group students and their opinions and thoughts were received about the application. Video recordings that were taken during the interviews and observations, the content analysis was made and it was analyzed.

\subsection{Design and Development}

In ARGE3D software that was developed by using Microsoft Silverlight and Slartoolkit Library, first the drawings related to geometric objects on the book were designed as a three-dimensional with 3DS Max and then were saved as ".ase" file. The user placed the markers on cube for the realization of user-computer interaction. As seen in Figure 1, first of all, users choose the page number and type of book with augmented reality (textbook, workbook) and then hold the marker to the camera and can display. Each marker represents a 3D geometric drawing. Marker patterns were created through the website http://Flash. Toratoro.org and due to the perception of markers that are on a white background, these markers were placed on white background on the cube.

$3 \mathrm{D}$ geometry book software can be used in web environment and it was converted to Windows Installer package by using Microsoft Visual Studio Install Shield 2012 program. Thus, the installer packages to be distributed to users were created and distributed to students to install them on their personal computers. In ARGE3D software, first of all, video stream from the camera is received. Then, the intensity of the markers in the received image were scanned and the location and position of the markers were calculated that were determined. The determined markers were compared with the markers present in the memory and 3D 
image was determined which was represented by the marker. Finally, 3D image was added to the marker's position and location and current video stream and the enriched image was displayed on the user's screen.
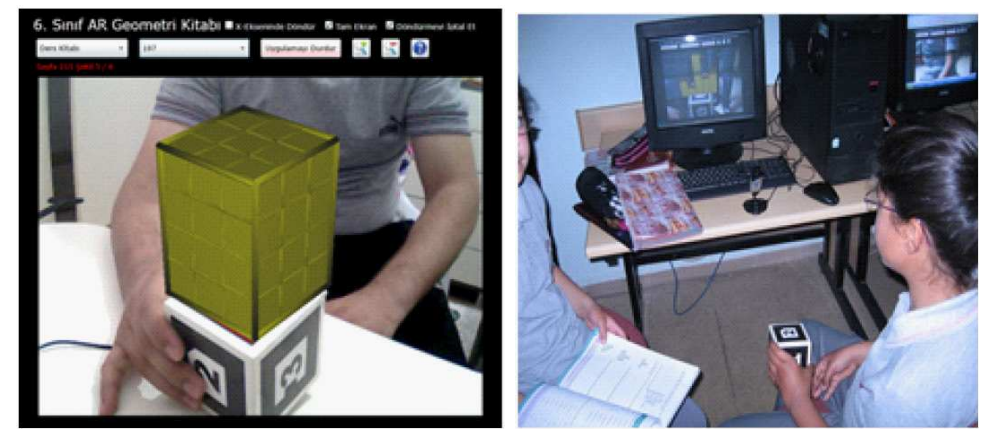

Figure 1. The internal use of markers on the cube

ARGE3D geometry book software and 3D image of the object can only be seen by interacting with the cube without using the arrow keys and computer mouse from all angles and the sizes of these images can be made larger or smaller. The application lasted 4 weeks and had two hours per week in a class environment with a computer and projector and the other two hours per week was in a computer laboratory environment. In Table 1, 11 learning objectives related with the geometry instruction are presented. During the application teachers primarily reflected the AG image of the three-dimensional shape that was located in the textbooks' and exercise books' geometric objects unit and then they asked the students to examine these materials in their own computers. Examples of classroom activities are given in Figure 1. Teachers and students handled static drawings both in the textbook and workbook with ARGE3D in a dynamic and interactive way and they displayed them three-dimensional.

\section{Results And Discussion}

Mann-Whitney U test was used in intergroup comparison for geometry level of thinking, mathematics and geometry achievement level (parametric test assumptions cannot be provided). When geometry level of thinking were examined, 1st school students in the experimental group compared to the control group of the order of the average higher, although this difference was not significant. Other 
schools in the control group and the experimental group students according to the order of the averages were seen to be significantly higher $(\mathrm{U}=178.5, \mathrm{p}<$ $0.05)$. When we look at mathematics achievement levels, only second average of the sequence of the control group students in the school from the experimental group were found to be significantly higher $(\mathrm{U}=140, \mathrm{p}<0.05)$. When we look at the geometry level of achievement after the experimental procedure, there was no significant difference between intergroup. In [38, 39], researchers defined that AR environments create more in depth learning by providing different angles of view of the difficult systems or objects. Bujak et al. stated that abstract concepts and physical objects have symbolic fond that are difficult to learn, it also combines discrete pieces of information and decreases the cognitive load, they help to discover events with interactive 3D simulations and in-depth learning [22]. Other researchers have supported these findings [20, 40- 41]. AR technologies suitable environment, supported by teachers and teaching to the students' academic achievement, spatial skills, critical thinking can be said to contribute to learning and exploring. Fonseca et al. stated that in order to be successful supported by AR technology in education, the teaching staff should give their full time, should spend some needed time, should be willing to and should be trained [29]. Otherwise, if they are not motivated with a suitable environment and teacher, the application success will decrease, the student will have a lack of interest and there will be a negative judgment for related technology.

For the attitudes of mathematics, before and after the experiment, the comparison of intergroup was made by two factor ANOVA. Firs, schools try to score in the experimental group iterations before it is seen that a significant increase in post-test $(\mathrm{F}(1,52)=4.58, \mathrm{p}<0.05)$. Other schools do not show a significant difference is observed that the recurrence score. Duplicates the average of scores obtained from the total score is still when viewed significant differences were found in school $1(\mathrm{~F}(1,52)=11.326, \mathrm{p}<0.05)$ were not significantly different in other schools. When we look at qualitative findings, teachers are forced to use the first week in other weeks will affect the research it was found that any problems encountered. Some students disagreed with her friends during use, during imaging technologies friend's AR is not successful enough, and stated that this situation affects them. Students' personal interests, perspectives and experiences may vary with that of other students. Therefore AR does not always make a positive impact in collaborative applications [22]. Mahadz and Phung found that Popup Book name, they augmented reality aided English story books with the education of the students, some students' low knowledge of English because of the 
motivation drops, the other students the motivation increase [25]. On the other hand, Gutierrez et al. found that at the end of the study supported by AR book, teaching students develop a positive attitude towards the AR assisted instruction [23]. Also, Bujak et al. stated that used in mathematics education the AR technology with face to face interaction environment creates the student's own perspective with these materials and over control can be used and, that would be easy for this reason, students change their perceptions and motivation to be effective in enhancing [22]. Fonseca et al. found that AR application that is used by mobile devices and advanced visualization technology increased the participation and motivation of the students [29]. Again, many researchers expressed that AR supported education applications increase the motivation of the student $[27,30]$. However, Wojciechowski and Cellary stated that their positive attitudes towards AR technology is based on being new technology and they will lose this positive attitude in time [28].

In findings related to AR technologies teaching, teachers stated that students' motivations are based on this and this have a contribution on their learning and attitudes towards mathematics. When compared to quantitative data, in the first school, it has a positive effect on the mathematics attitudes and their academic achievement. However, while its impact is significant towards mathematics, its impact on academic achievement is not significant. In the second school, it has significant and positive effect on academic achievement of the students, but it has no significant effect on their attitudes. Teachers stated that it has a positive effect on the attitudes of the students that have negative attitudes towards mathematics, and on the students that have positive attitude, there is no positive or negative effect. In addition, teachers and students stated that the abstract mathematical knowledge can be easily embodied in the mind with the use of AR technology and students can learn topics much faster and so, they can solve more examples in the lessons. It was also stated that, in this context, AR technologies provide additional time for teachers, the students' misconceptions due to the missing or unclear drawings drawn by teachers or students decreased in AR supported education.

Considering the intensions to use AR technologies, it was requested to be developed for the other subjects of the mathematics, physics and chemistry courses. In addition, teachers and students stated that AR technologies are different from other dynamic geometry software, due to the physical interaction in AR, students' attention and interest is high and teachers also stated that it provides a richer learning opportunities. Students stated that they feel like playing game 
with AR and due to this, the lessons are more enjoyable. These findings support the results of other studies where the AR technologies have positive effect on students' attitudes towards lessons stated [22, 25, 27, 38, and 39]. According to Domínguez et al., the levels of satisfaction of the students that are educated by virtual reality and PDF3D technologies are similar, the satisfaction levels of AR educated students are higher than the students in the other group [32].

\section{References}

[1] N. Y. Köse, İlköğretim 5. sınıf öğrencilerinin dinamik geometri yazılımı Cabri geometriyle simetriyi anlamlandırmalarının belirlenmesi: bir eylem araştırması, unpublished doctoral dissertation, Institute of Education Sciences Anadolu University, Eskisehir, 2008.

[2] M. Bako, Different projecting methods in teaching spatial geometry, in: Electronic Proceedings of the 3rd Congress of the European Society for Research in Mathematics Education, (M. A. Mariotti, ed.), Bellaria, Italy, 28 February - 3 March 2003.

[3] A. Baki, T. Kösa and F. Karakuş, Using dynamic geometry software to teach solid geometry: Teachers' views, in: Proceedings of 8th International Educational Technology Conference, Eskişehir, Turkey, 9. May 2008, 82-86.

[4] M. T. Battista and D. H. Clements, Students' understanding of three-dimensional rectangular arrays of cubes, Journal for Research in Mathematics Education 27, no. 3 (1996), 258-292, ISSN. 0021-8251.

[5] W.-Y. Hwang, J.-H. Su, Y.-M. Huang and J.-J. Dong, A study of multi-representation of geometry problem solving with virtual manipulatives and whiteboard system, Educational Technology \& Society 12, no. 3 (2009), 229-247, ISSN: 1436-4522.

[6] A. Rafi, K. A. Samsudin and C. Soh, Training in spatial visualisation: The Effects of training method and gender, Educational Technology \& Society 11, no. 3 (2008), 127-140, ISSN: 1436-4522.

[7] J. Piaget, Biology and knowledge: An essay on the relations between organic regulations and cognitive processes, U. Chicago Press, Oxford, England, 1971, ISBN: 9780226667751.

[8] J. Bruner, In search of pedagogy: The Selected Works of Jerome Bruner, New York, NY: Taylor \& Francis Group, 2006, ISBN: 0-415-38675-6.

[9] R. G.ürbüz and M. Gülburnu, 8. sınıf geometri öğretiminde kullanılan cabri 3D'nin kavramsal öğ renmeye etkisi, Turkish Journal of Computer and Mathematics Education 4, no. 3 (2013), 224-24.

[10] A. Rafi, K. A. Samsudin and A. Ismail, On improving spatial ability though computer-mediated engineering drawing instruction, Educational Technology 6 Society 9, no. 3 (2006), 149-159. 
[11] L. Fahlberg-Stojanovska and Z. Trifunov, Constructing and exploring triangles with GeoGebra, Annals. Computer Science Series (Anale. Seria Informatică) 8, no. 2 (2010), 45-54.

[12] N. Selçik and G. Bilgici, The effect of the GeoGebra software on students' academic achievement, Kastamonu Educational Journal 19, no. 3 (2011), 913-924.

[13] N. Arbain and N. A. Shukor, The effects of Geogebra on students achievement, Procedia-Social and Behavioral Sciences 172 (2015), 208-214.

[14] B. Güven and T. Kösa, The effect of dynamic geometry software on student mathematics teachers' spatial visualization skills, The Turkish Online Journal of Educational Technology 7, no. 4 (2008), 100-107.

[15] M. Eraso, Connecting visual and analytic reasoning to improve students' spatial visualization abilities: A constructivist approach, Doctoral dissertation, Florida International University, 2007.

[16] B. Yıldız, The effects of using three-dimensional virtual environments and concrete manipulatives on spatial visualization and mental rotation abilities, Unpublished Masters' dissertation, Hacettepe University, Ankara, Turkey, 2009.

[17] G. Güneş, Yeni ilkögretim matematik dersi öğretim programının ögretme öğ renme ortamına yansimaları, Unpublished doctoral dissertation, Institute of Science, Karadeniz Teknik Üniversity, Trabzon, 2008.

[18] J.-C. Gonzato, T. Arcila and B. Crespin, Virtual objects onreal oceans, GRAPHICON'2008, Russie, Moscou (December, 2008), 49-54.

[19] R. T. Azuma, A survey of augmented reality, Teleoperators and Virtual Environments 6, no. 4 (1997), 355-385, ISSN 1531-3263.

[20] M. Dunleavy, C. Dede and R. Mitchell, Affordances and limitations of immersive participatory augmented reality simulations for teaching and learning, Journal of Science Education and Technology 18, no. 1 (2009), 7-22, ISSN: 1059-0145.

[21] J. Lave and E. Wenger, Situated learning: legitimate peripheral participation, Cambridge University Press, England, 1991, ISBN: 0009-8388.

[22] K. R. Bujak, I. Radu, R. Catrambone, B. MacIntyre, R. Zheng and G. Golubski, A psychological perspective on augmented reality in the mathematics classroom, Computers $\mathcal{E}$ Education 68 (2013), 536-544, ISSN: 0360-1315.

[23] J. Martin-Gutierrez, J. Luís Saorín, M. Contero, M. Alcaniz, D. C. Perez-Lopez and M. Ortega, Design and validation of an augmented book for spatial abilities development in engineering students, Computers $\mathcal{E}$ Graphics 34, no. 1 (2010), 77-91, ISSN: 0097-8493.

[24] Y. H. Chang and J.-C. Liu, Applying an ar technique to enhance situated heritage learning in a ubiquitous learning environment, The Turkish Online Journal of Educational Technology 12, no. 3 (2013), 21-32, ISSN: 1303-6521.

[25] N. Nashirah, N. Mahadzir and L. F. Phung, The use of augmented reality pop-up book to increase motivation in english language learning for national primary school, Journal of Research ES Method in Education 1, no. 1 (2013), 26-38, ISSN 1476-7341. 
[26] D. Serio, M. B. Ibanez and C. D. Kloos, Impact of an augmented reality system on students motivation for a visual art course, Computers 8 Education 1, no. 11 (2012), 586-596, ISSN: 0360-1315.

[27] A. M. Borrero, M. Mejias and J. M. Andujar, A pilot study of the effectiveness of augmented reality to enhance the use of remote labs in electrical engineering education, Journal Of Science Education And Technology 21, no. 5 (2012), 540-557, ISSN: $1464-5289$.

[28] R. Wojciechowski and W. Cellary, Evaluation of learners' attitude toward learning in ARIES augmented reality environments, Computers \& Education 68 (2013), 570-585, ISSN: 0360-1315.

[29] D. Fonseca, N. Marti, E. Redondo, I. Navarro and A. Sánchez, Relationship between student profile, tool use, participation, and academic performance with the use of augmented reality technology for visualized architecture models, Computers in Human Behavior 31 (2013), ISSN: 0747-5632.

[30] H. Kaufmann and D. Schmalstieg, Mathematics and geometry education with collaborative augmented reality, Computers \& Graphics 27 (2003), 339-345, ISSN: 0097-8493

[31] S. M. Banu, Augmented realitys system based on Sketches for geometry education, International Conference on E-Learning and E-Technologies in Education (ICEEE) (2012), 166-170.

[32] M. G. Domingueza, J. Martin-Gutierrezb, C. R. Gonzaleza and C. M. Mato Corredeaguasc, Methodologies and tools to improve spatial ability, Procedia-Social and Behavioral Sciences 51 (2012), 736-744, ISSN: 1877-0428.

[33] Z. Usiskin, Van Hiele levels of achievement in secondary school geometry, in: Final Report of the Cognitive Development and Achievement in Secondary School Geometry Project, University of Chicago, Chicago, 1982.

[34] A. Duatepe, An investigation of the relationship between van hiele geometric level of thinking and demographic variable for pre-service elementary school teacher, Unpublished Master's Thesis, Middle East Technical University, Ankara, 2000.

[35] P. Aşkar, Matematik dersine yönelik tutumu öl çen likert-tipi bir ölçeğin geliştirilmesi, E ğitim ve Bilim 62, no. 11 (1986), 31-36, ISSN: 1300-1337.

[36] L. L. Davis, Instrument review: Getting the most from a panel of experts, Applied Nursing Research 5, no. 4 (1992), 194-197, ISSN: 0897-1897.

[37] J. W. Creswell, Research design: Qualitative, quantitative and mixed methods approaches, Sage Publications, Thousand Oaks, CA, 2003, ISBN: 1350-5084.

[38] K.-F. Hsiao and H. F. Rashvand, Integrating body language movements in augmented reality learning environment, Human-Centric Computing and Information Sciences 1, no. 1 (2011), 1-10, ISSN: 2192-1962.

[39] L. Kerawalla, R. Luckin, S. Seljeflot and A. Woolard, Making it real: Exploring the potential of augmented reality for teaching primary school science, Virtual Reality 10, no. 3 (2006), 163-174, ISSN: 1434-9957. 
[40] K.-H. Cheng and C.-C. Tsai, Affordances of augmented reality in science learning: Suggestions for future research, Journal of Science Education and Technology 14, no. 1 (2012), 449-462, ISSN: 1464-5289.

[41] P. O'Shea, C. Dede and M. Cherian, The results of formatively evaluating an augmented reality curriculum based on modified design principles, International Journal of Gaming and Computer-Mediated Simulations 3, no. 2 (2011), 57-66, ISSN: 1942-3888.

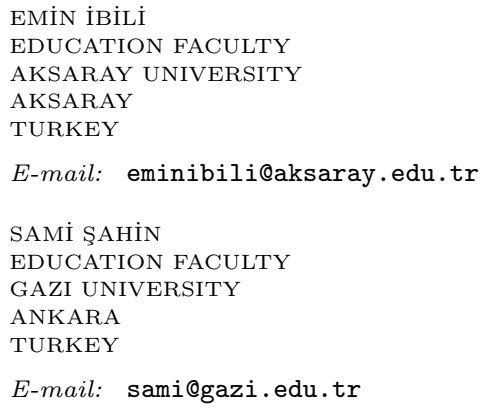

(Received February, 2015) 